\title{
SAFETY EQUIPMENT FOR STORAGE AND HANDLING OF CHEMICALS IN UNIVERSITY LABORATORIES
}

\author{
JOSE MORA, JOSE SIBAJA, WENDY UMAÑA, GILBERTO PIEDRA \& OSCAR MOLINA \\ Department of Chemistry, National University, Costa Rica
}

\begin{abstract}
Persons who work in scientific laboratories must deal with different types of hazards. The main objective of laboratory safety operations is the prevention of accidents and emergencies. However, the potential for accidents is real, and when they take place, good safety equipment and adequate emergency protocols can help to minimize injuries or damages. The main purpose of this research was to determine the quantity of laboratories that had in their facilities any safety materials and equipment, in order to evaluate the necessity to install new equipment according to; 1) the descriptions of operations and tasks related to the handling, storage, and disposal of hazardous materials in the laboratories, and, 2) a list of potentially hazardous substances, including toxic chemical, biological, and physical agents that might cause harm to a facility's employees. In order to get such information, a diagnosis of health and safety equipment and material availability, and their management in academic instructional and research laboratories was carried out in 91 laboratories. According with the results obtained, the hazardous products stored in biological and clinical laboratories are mainly infectious products. In chemical laboratories, flammable substances are the most common hazard chemicals stored, and physical laboratories mainly stored corrosive chemical products. In general, the majority of flammable, toxic, corrosive and explosive products are localized in chemical laboratories. Most of the laboratories inspected did not have adequate storage facilities for flammable, toxic, explosive and corrosive products. Some had "solvent rooms" with quite inadequate facilities, and in the absence of adequate solvent cabinets, fume hoods or open shelving were used for storage. The inspection and training processes, as well as the purchase and installation procedures used, made the laboratories safer through the use of best practices and protective equipment. However, the restricted space in laboratories also makes it difficult to install some safety equipment. The need for, and possibility of installation of, other systems such as fire alarms, smoke detectors, and emergency exits must be evaluated. Careful handling and use of chemicals, together with the availability of adequate and proper safety equipment, and the application of good practices in housekeeping and personal hygiene, will greatly reduce the probability and severity of injuries.

Keywords: safety equipment, laboratory, chemical substances, storage, hazardous materials and products, university, Costa Rica.
\end{abstract}

\section{INTRODUCTION}

Persons who work in scientific laboratories must deal with different types of hazards. Even though this is true for many types of workplaces, laboratories present a greater variety of hazards than other workplaces, and some types of hazards that are rarely found outside laboratories [1]. There are four general types of laboratories specified in the ASHRAE Handbook-HVAC Applications: 1. Biological: Contain biologically active materials and include areas such as biochemistry, cell biology, immunology, pharmacology, microbiology, and related fields, 2. Chemical laboratories: Support both organic and inorganic synthesis and analytical functions, 3. Clinical/Animal laboratories: Include areas for the observation, manipulation, and pharmacological observation of laboratory animals, as well as animal holding rooms, and 4. Physical laboratories: spaces associated with physics, including lasers, optics, high and low temperature materials, and analytical instruments [2].

People who work in laboratories in which chemicals are manipulated (for example, chemical and biological laboratories) must be prepared to deal with substances which are 
known to be hazardous, with new substances which may present unknown hazards, and with new kinds of experiments. As opposed to chemical manufacturing plants, laboratories generally handle only small amounts of materials, and exposures to particular materials take place for short periods of time, usually less than 8 hours per day. In this regard, there is little difference between industrial and academic laboratories. Higher educational institutions such as universities must manage not only research and analytical laboratories, but also teaching laboratories, in which new students and workers must be introduced to the safety precautions and effective health and safety programs needed for laboratory operations [1]. It is also important to note that the field of health and safety continues to grow in complexity and the job of managing risks to maintain a safe, healthful workplace becomes increasingly challenging as new data and new knowledge about hazards in scientific laboratories and other workplaces become available [3].

Research and teaching laboratories are workplaces which have particular health and safety requirements. The nature of the facilities, the laboratory operators (workers and students), and the tasks being carried out all differ noticeably from the tasks performed in industrial workplaces. Nonetheless, the requirements for adequate health and safety procedures in these laboratories are very real, and no less relevant than those required for programs and procedures in the industrial sector [3]. It is not possible to establish a single set of rules that will cover all potential laboratory hazards and risks. Working safely is the most important requirement that must be met by all laboratory personnel, including laboratory directors, laboratory operators, students and visitors. Every person must accept responsibility for performing laboratory work according to appropriate safety procedures, and must be aware in advance of potential risks, what emergency aids are available, and how they are to be handled and used. Laboratory directors have the main responsibility for assuring, among other things, that: a) safety procedures are followed by all workers, b) suitable emergency and personal protection equipment and safety materials are available and fully operational, c) training in the use of emergency equipment and materials has been provided, d) training about special or unusual hazards in non-routine work has been given to the laboratory workers and e) adequate safety training has been provided to individuals when they begin their work in the laboratory [1],[4],[5].

In the cases of availability of adequate equipment for emergencies and personal protection, and safety materials in the laboratory, a wide variety of specialized clothing and equipment is commercially available for use in these workplaces. Correct use of these items decreases or eliminates exposure to the hazards associated with many laboratory tasks. The main objective of laboratory safety operations is the prevention of accidents and emergencies. However, the potential for accidents is real, and when they take place, good safety equipment and adequate emergency protocols can help to minimize injuries or damages. A laboratory must be provided with the following safety equipment; spectacles and face shields, gloves, respiratory protective equipment, safety showers and eyewash stations, fire safety equipment, special cabinets to store chemicals in laboratory areas, chemical fume hoods and with biological safety cabinets [1], [4], [5].

Spectacles and face shields: Eye protection must be used for all personnel, and any visitors, in locations where chemicals are stored or handled. Minimum acceptable eye protection requires the use of hardened glass or plastic safety glasses with a minimum lens thickness of $3 \mathrm{~mm}$, good resistance to impacts and flames, and lens-retaining frames. Cellulose nitrate frames should never be used [1], [4]. Gloves: These should be available and always used to handle corrosive materials, rough or sharp-edged objects, very hot or very cold materials, or whenever protection is needed against accidental exposure to chemicals [1], [4]. A wide variety of gloves are commercially available. Leather gloves may 
be used for handling broken glassware, for inserting glass tubes into rubber stoppers, and for other operations where protection from chemicals is not needed. [1], [4], [5].

Respiratory protective equipment: The most important way to protect laboratory workers from airborne contaminants is to minimize the amount of pollutants in the air in laboratory areas through good work procedures and correct use of laboratory fume hoods. In the absence of adequate air extraction systems, adequate respiratory protection should be available [1]-[5]. The term "respirator" refers to any device that covers the nose and mouth to prevent the inhalation of harmful substances. All respirators are not equal. Respirators range from disposable dust respirators to self-contained breathing apparatus [1]-[5].

Safety showers and eyewash station: A laboratory must be equipped with safety showers and eyewash stations, installed close to where laboratory workers may be using potentially hazardous substances. The safety showers and eyewash station location and the ways in which employees are trained to use them must meet all relevant regulations. A facility's health and safety officer should evaluate the particular needs of each work site in relation to hazards, regulations, and building design, and then recommend the best equipment for each laboratory within the facility [3]-[5].

Fire safety equipment: This includes a wide range of extinguishers, along with hoses, blankets, and fire detection and automatic extinguishing systems. In the case of fire extinguishers, chemical laboratories should be equipped at a minimum with carbon dioxide and dry chemical fire extinguishers. Other types of extinguishers should be used according to the laboratory procedures being carried out. Fire hoses are intended to be used by trained firefighters against fires which are too large to be handled by extinguishers. Many laboratories also have fire blankets available, even though their usefulness is limited. A fire blanket is used principally as a first aid measure for the prevention of shock, rather than to control smoldering or burning clothing. It should be used only as a last option to extinguish clothing fires, as blankets tend to enhance the severity of burns. Finally, automatic systems for detecting and extinguishing fires are often used in areas of high fire potential and high risk of injury or damage. These systems may make use of water sprinklers, carbon dioxide, dry chemicals, or halogenated hydrocarbon. Where they are installed, laboratory personnel should be informed of their presence and type, and be trained in any safety precautions required for their use and operation [1]-[5].

Special cabinets to store chemicals in laboratory areas: The safe storage of hazardous chemicals is an essential part of an environmental, health, and safety program. Laboratories on campus must observe several requirements that incorporate safe storage, such as: keeping an up-to-date chemical inventory, maintaining a chemical hygiene plan, documenting staff training, and conducting annual self-inspections [6], [7]. A number of facilities are used for the storage of chemical substances, some of which are specially designed for the purpose. These special-purpose facilities include a) cabinets for corrosive substances, made of acid-resistant materials; they should have a tray to contain any leakage or spillage; b) flammable solvent cabinets: These are designed to maintain the temperature at the top center of the cabinet interior below $324^{\circ} \mathrm{F}$ when subjected to a 10 minute fire test, and c) ventilated cabinets for toxic substances: These are cabinets fitted with forced ventilation, and may be free-standing with their own extraction system or positioned beneath a fume cupboard and attached to its duct. The most important aspect to take into account when using storage cabinets is that they must be only of types that conform to relevant regulations and are approved by the institution [6], [7].

Chemical fume hoods: Some common types of fume hoods available in biological and chemical laboratories include: 1) standard fume hoods (constant-volume exhaust airflow with variable face velocity), 2) bypass fume hoods (constant-volume exhaust airflow), 
3) variable-volume fume hoods (constant face velocities), and 4) auxiliary air fume hoods (constant-volume exhaust airflows with $50 \%$ to $70 \%$ makeup air delivered directly to the hood) [2]. Biological safety cabinets: these are special equipment used for work with cell and tissue cultures and parenteral drugs when the products being manipulated must be kept in a sterile environment, and the worker must be protected from toxic substances and infectious biological agents. Biological safety cabinets are designated as Class I, II and III, according to the level of pollutant involved. Class II cabinets are the most used, and are further subdivided according to the quantity of airflow and the construction of the cabinet into types A, B1, B2 and B3 [8], [9].

The availability of safety equipment and materials within laboratory facilities, together with their control, inspection, use and training, are elemental considerations when developing a Chemical Hygiene Plan (CHP) or preparing for emergencies. The CHP must incorporate laboratory protocols for responding to chemical exposure emergencies. Hence, the CHP should point out the location and proper use of safety materials and equipment in the laboratories. It should also include a description of the maintenance, inspection, and testing procedures in place for safety equipment [3]. Similarly, when preparing for emergencies, it is the responsibility of each laboratory organization to set up a specific emergency plan. The plan should incorporate the explanation of evacuation routes and safety areas, location of safety materials and equipment, and procedures for reporting all accidents and emergencies [1]. Bearing these points in mind, the main purpose of this research was to determine the quantity of laboratories that had in their facilities any safety materials and equipment, in order to evaluate the necessity to install new equipment according to; 1) the descriptions of operations and tasks related to the handling, storage, and disposal of hazardous materials in the laboratories, and, 2) a list of potentially hazardous substances (i.e., a chemical substances inventory), including toxic chemical, biological, and physical agents that might cause harm to a facility's employees.

The main purpose of this research was to determine the quantity of laboratories that had in their facilities any safety materials and equipment, in order to evaluate the necessity to install new equipment according to; 1) the descriptions of operations and tasks related to the handling, storage, and disposal of hazardous materials in the laboratories, and, 2) a list of potentially hazardous substances, including toxic chemical, biological, and physical agents that might cause harm to a facility's employees.

\section{METHODOLOGY}

The National University of Costa Rica (UNA-CR) is a public university founded in 1973, with 10,000 workers and 32,000 students. The Chemical Management Office (CMO) was created in 2006, and works to promote efficient chemical products handling, environmental health and safety (EH\&S) programs, and other related activities. Among other units, the UNA-CR contains three faculties related to chemical analytical procedures. These university faculties are related to the following scientific fields: chemistry, biology, agriculture, veterinary medicine, toxicology, environmental sciences, and soils and forests.

With the principal objective of improving laboratory safety, in 2010 the CMO began the implementation of a strategy for evaluating laboratory working conditions in order to equip them with the necessary health and safety equipment and materials. The strategy included the following steps. 
2.1 Health and safety equipment and materials availability in laboratories (Initial Diagnosis)

During 2010, a diagnosis of health and safety equipment and material availability, and their management in academic instructional and research laboratories was carried out in 91 laboratories, using the following tools: (1) Administration of a questionnaire (personnel of different laboratories filled out a form with answers to questions related to health and safety equipment); (2) an inspection visit to the laboratories; (3) work sessions with university management authorities; (4) consultation with stakeholders/private industry.

\subsection{Data analysis}

The information gathered during the diagnosis was analyzed during year 2011 by the CMO together with health and safety experts in order to identify: a) Types of laboratories (According to ASHRAE Handbook-HVAC), b) Potentially hazardous materials (i.e., a hazardous materials inventory), that might cause harm to a facility's employees, c) Operations and tasks involved in the handling, storage, and disposal of hazardous materials, d) Control measures (e.g., types of personal protection equipment, engineering controls, and administrative controls such as training and personnel rotation), e) Safety materials needed for each laboratory and f) Facilities' physical conditions for the installations of safety equipment and materials.

\subsection{Training}

Individual as well as general training was carried out during the years 2011-2012 to discuss the data gathered during the diagnosis. Faculty, staff, department directors, general laboratory operators (students and workers), purchasing staff, financial staff and others were trained in important aspects of health and safety. Based on the complex regulatory requirements of the Occupational Safety and Health Administration (OSHA) and the Environmental Protection Agency (EPA), the training included topics such as the following: a ) Health and safety at work, b) Regulations for management of health and safety at work, c) The workplace (Health, Safety and Welfare), e) The provision and use of work equipment, f) Personal protection equipment and its management, h) Safety equipment and materials and their management, i) The correct use of safety materials, j) Purchasing of safety materials and personal protection equipment and k) Preventive and corrective maintenance for safety materials and personal protection equipment.

\subsection{Health and safety equipment's purchase and installation}

Based on the results of the diagnosis, the analysis of those results, and the results of training, in 2013 the $\mathrm{CMO}$ began the process of purchasing the necessary safety equipment and materials for each of the laboratories evaluated. The corresponding installation process was carried out in the year 2014 and the first trimester of 2015. During the installation process, data gathered during the first diagnosis were updated.

\section{RESULTS AND DISCUSSION}

Fig. 1 indicates the type of laboratories within the UNA-CR (based on the ASHRAE Handbook Applications-HVAC). Biological laboratories represent $42 \%$ of the total number of laboratories in the university; these working areas belong to two faculties (the Soil and Forest Faculty and the Natural Science Faculty). A total of 26 of the 91 


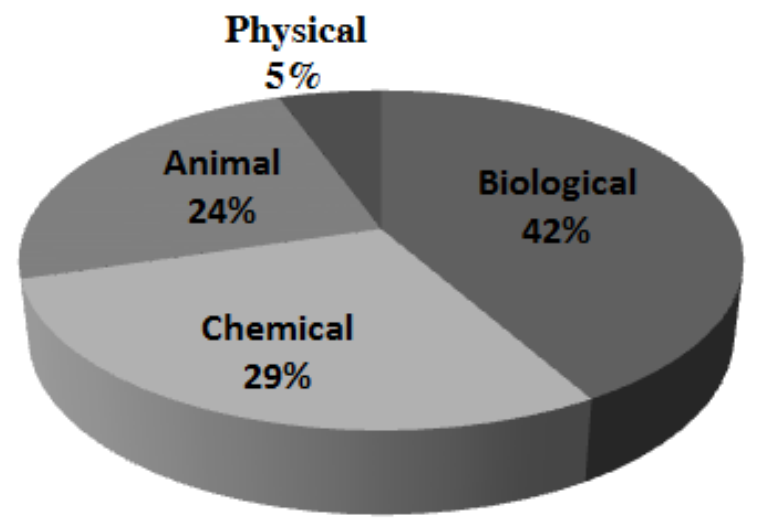

Figure 1: Percentage distribution of laboratories within the UNA-CR using the ASHRAE HVAC classification, 2010.

laboratories evaluated are classified as chemical laboratories, and most of them (16 laboratories) belong to the Natural Science Faculty. Only 5\% of the laboratories are categorized as physical laboratories. In the case of clinical/animal laboratories, all are situated in the Health Science Faculty, specifically in the Veterinary Department.

The percentage distribution of chemical products stored and used in the different laboratories classified according to the ASHRAE Handbook Applications is shown in Fig. 2. The chemical products were categorized according to their hazardous properties (i.e., flammables, toxics, infectious, corrosives and explosives). The hazardous properties were analyzed by using; 1) a register of potentially hazardous materials (i.e., a hazardous materials inventory) that may cause harm to facility employees and, 2) a description of operations and tasks involved in the handling, storage, and disposal of hazardous materials. According to Fig. 2, biological laboratories used large amounts of infectious products, which are related to microbiological procedures.

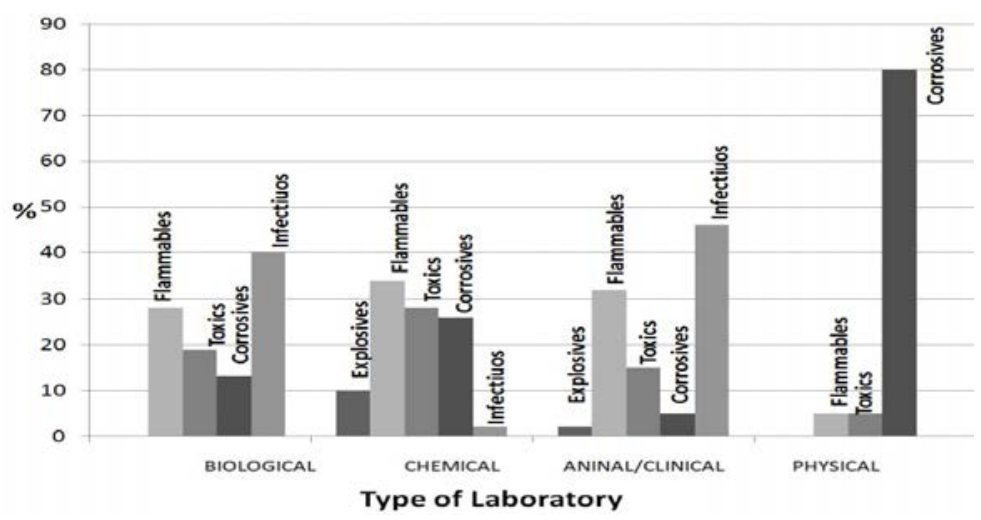

Figure 2: Percentage distribution of explosives, flammables, toxics, corrosives and infectious products stored at Biological, Chemical, Clinical and Physical Laboratories, UNA-CR, 2010. 
However, some flammable products such as phenol and ethanol are also used for disinfection procedures. Corrosive products such as strong acids are also manipulated within biological laboratories, while the most often used substances in chemical laboratories are flammable, toxic and corrosive in nature. All work sites belonging to chemical laboratories carry out many chemical analytical procedures, where flammable chemical reagents such as methanol, ethanol, phenol, benzene, aldehydes and ketones are stored and used. Toxic compounds are also frequently used in chemical laboratories. Fig. 2 shows indicates that Clinical/animal laboratories have a profile similar to that of biological laboratories, with the most frequently used chemicals falling in the flammable and infectious categories. In the case of the Veterinary Department, a large quantity $(10,000$ liters) of formaldehyde is consumed annually to preserve carcasses which are studied in research and academic laboratories. Finally, physical laboratories mainly handle corrosive chemicals such as sulphuric acid and mercury salts (toxic products) and ethanol (a flammable product), which are used during academic classes.

An overview of the percentage distribution of all hazardous products used within the University is shown in Fig. 3. Explosive materials are only used in chemical and clinical laboratories; $90 \%$ are stored in chemical laboratories and the other $10 \%$ in clinical laboratories. Flammable products are stored in biological, chemical, clinical and physical laboratories. The highest percentage $(65 \%)$ of flammable products is located in chemical laboratories, while less than $5 \%$ of flammable materials are stored in physical laboratories. Toxic products such as toluene, esters, ethers, mercury and cadmium salts, chromium and acetonitrile are also used in chemical, biological and clinical laboratories. Biological laboratories stored $16 \%$ and clinical laboratories accumulated $23 \%$ of toxic products. In the case of corrosive materials, less than $10 \%$ are used outside chemical laboratories. Physical laboratories mainly handle corrosive chemicals (3\%) such as sulphuric acid, which is used to evaluate corrosion of metals. Infectious products are mostly used in biological and clinical laboratories, mainly when carrying out microbiological procedures.

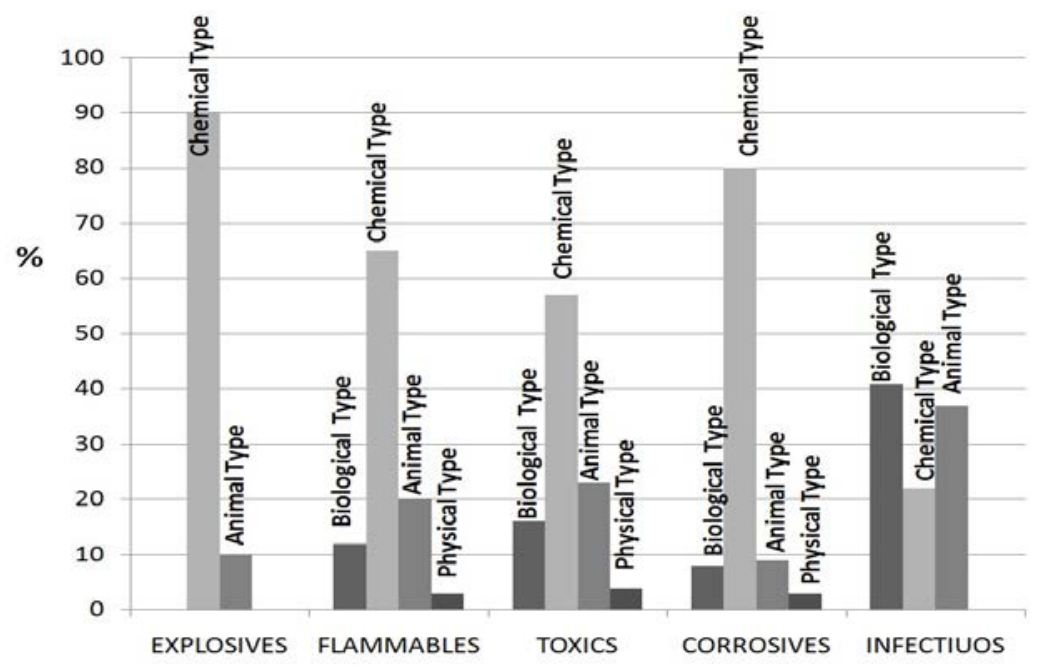

Figure 3: Percentage distribution of hazardous products within the University, 2010. 
The availability of safety equipment and materials within the laboratory facilities is shown in Fig. 4, which indicates the number of laboratories which have any kind of safety equipment during year 2010. The names and acronyms of the equipment used in Fig. 4 are as follows; Safety shower and eye wash station (SS/EW), Fire safety equipment (FSE), Special cabinets (SC), Chemical fume hoods (CFH), Biological safety cabinets (BSC) and Neutralizers $(N)$. In the case of FSE, only the availability of any kind of fire extinguisher (A, C, D or E types) in laboratories was evaluated. The "special cabinets" (SC) category refers to the availability in a laboratory of at least one special cabinet to store flammable, toxic or corrosive materials in working areas. In Fig. 4 the number of laboratories inspected in every single type of laboratory is shown in parentheses, e.g., Biological (38).

Fig. 4 indicates that the equipment named "FSE" is the most commonly available safety equipment in biological laboratories and animal laboratories. In the case of chemical laboratories, the most commonly available equipment is "CFH". According to this figure, indicates that 40 of the 91 laboratories inspected have some type of fire extinguisher with carbon dioxide or dry chemical available. Special cabinets are the least frequently available equipment in laboratories; only 4 of the 91 laboratories evaluated have this equipment.

With respect to the availability of safety equipment within biological laboratories, at least $10(26 \%)$ of the 38 sites inspected used some type of safety equipment such as "SS/EW", "FSE", "CFH" or "BSC". In the case of chemical laboratories, at least of $46 \%$ of the labs evaluated had some kind of safety materials classified as "SS/EW", "FSE" or "CFH". It is important to point out that over $55 \%$ of the chemical laboratories had a chemical fume hood to carry out analytical chemical procedures, which are very common in this kind of work site. In the case of animal/clinical laboratories, Fig. 4 shows that only one of 22 laboratories have a special cabinet to store flammable products such as ethanol. Workers in these laboratories also manipulated toxic products like formalin and phenol, but

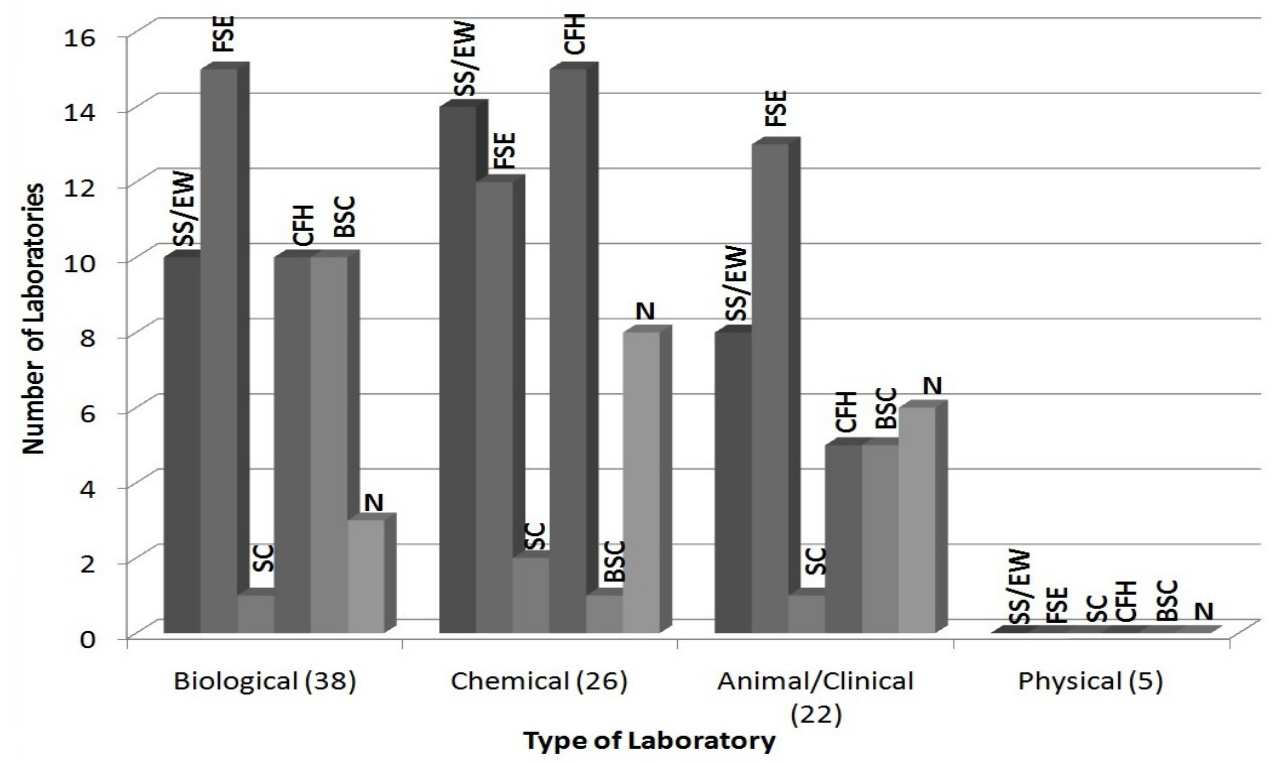

Figure 4: Safety equipment available at laboratories in the UNA-CR, 2010. 

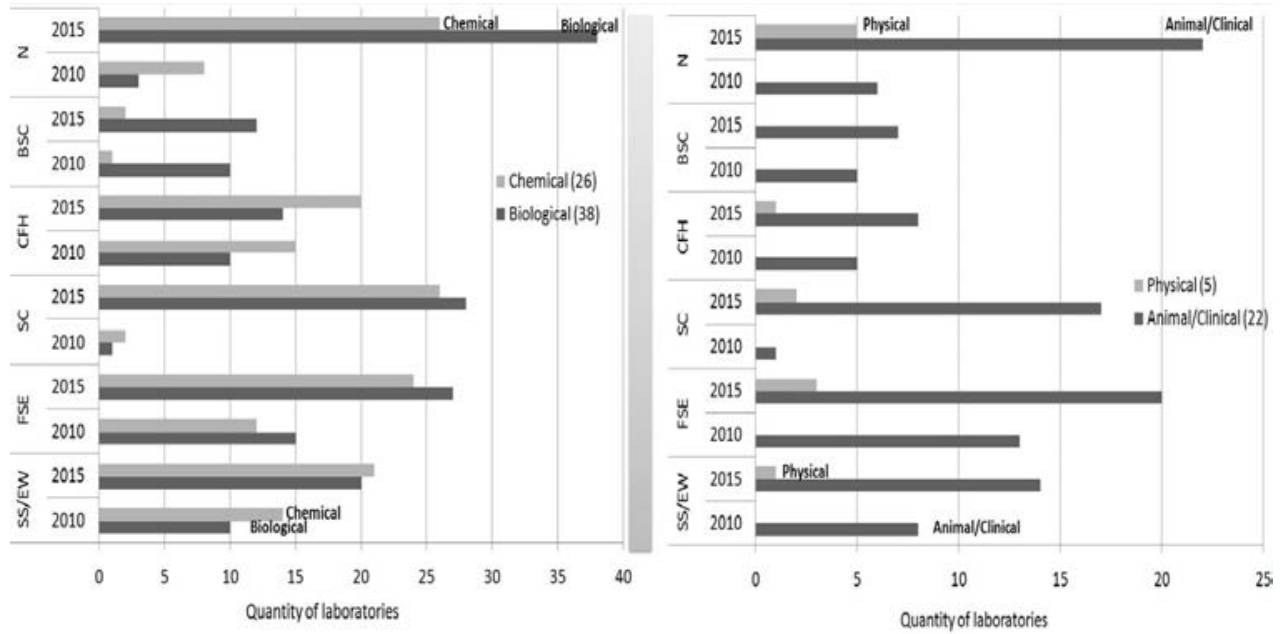

Figure 5: Comparison of the safety equipment availability at laboratories during years 2010 and 2001-2015 years, UNA - CR.

there were no special cabinets to store such substances. As shown in Fig. 4, the use of "BSCs" in biological and clinical laboratories is more necessary and common than in chemical and physical laboratories. Finally, no availability of safety equipment was found in physical laboratories, although chemicals are used in these locations.

Fig. 5 compares the safety equipment availability within laboratory facilities before and after inspection procedures, as well as before and after the training sessions developed for laboratory workers and other persons. The baseline corresponds to the year 2010: during that time safety equipment was acquired by the laboratory directors, but the criteria used to purchase this equipment were not sufficient to maintain a safe working environment.

During the year $2015100 \%$ (Fig. 5), of the laboratories have some kind of neutralizer. The equipment "SC" has an important, in the year 2010 only 4 laboratories had this equipment. However, for 2014 and 2015, 80\% of the sites inspected had or have special cabinets to store chemical products. The types of safety equipment which have least increased in the last 5 years are "BSC" and "CFH", which were installed only in 5 and 13 new work sites, respectively. During year 2010 only 16 laboratories had "biological safety cabinets", and only 30 sites had "chemical fume hoods". In 2015, a total of 21 laboratories have "BSC" and 43 laboratories have "CFH" for carrying out their different tasks. These values correspond to $23 \%$ (in the case of "BSC") and $47 \%$ (for "CHF") of the 91 laboratories evaluated. It is important to note that not all of the 91 laboratories need "BSCs" and "CFHs", for example, most of the biological laboratories do not require chemical fume hoods; instead, biological laboratories as well as clinical laboratories require biological safety cabinets, since their procedures fundamentally involve microbiological analysis.

In the case of biological laboratories, during the years 2014-2015, neutralizers, special cabinets and fire safety equipment were the types of equipment most frequently installed $100 \%, 74 \%$ and $71 \%$ of the laboratories were furnished with these types of equipment, respectively. Chemical fume hoods and biological safety cabinets showed a smaller increase compared to the other types of equipment installed in the biological laboratories, with only 4 new laboratories equipped with "CFHs" during that year. Over $80 \%$ of chemical laboratories were provided with equipment such as "SS/EWs", "FSEs", "SCs" 
and neutralizers during the years 2014-2015. Currently, a total of 24 of the 26 laboratories inspected have fire safety equipment in their facilities. In the case of animal/clinical labs "N" and "FSE" was the most acquire equipment. In respect to physical labs the main installed equipment's were also neutralizers for chemical spills.

\section{CONCLUSIONS}

At UNA-CR some laboratories were constructed before the issue of safety received as much attention as it does today. Because of this, indispensable safety equipment is either lacking or was incorporated after the construction of some of the laboratories that were evaluated. Laboratory operators pointed out during the evaluation and inspection processes that the purchase of equipment needed to be more seriously incorporated into the university budget. They also mentioned that adequate installation, maintenance, and use require both concern for, and knowledge of, laboratory safety.

The inspection and training processes made the laboratories safer through the use of best practices and protective equipment. Today, the majority of the working areas have; 1) adequate fixed protection systems to handle hazardous products, 2) fire extinguishers suitable for particular hazards in each location, 3) safety shower/eye wash stations, 4) neutralizers, 5) special cabinets to store flammable, toxic and corrosive chemicals, 6) fume hoods, and 7) biological safety cabinets for carrying out chemical analysis and microbiological procedures. However, there is still a need to equip more laboratories with "CHFs and BSCs", although some facilities do not have enough space to install this equipment correctly, especially when installing their ventilation systems, and water and electrical supplies. The restricted space in laboratories also makes it difficult to install safety showers/eye wash stations. The need for, and possibility of installation of, other systems such as fire alarms, smoke detectors, and emergency exits must be evaluated by the $\mathrm{CMO}$ in future inspections.

It is very important that the Chemical Management Office, together with laboratory coordinators, revise training programs about safety procedures on a semi-annual basis, with the main objective of keeping all employees up to date on new rules and facilities. Finally, it is important to point out that employee safety within a laboratory depends upon workers' attitudes, the safety protocols implemented in the laboratory, and the safety equipment available in the facility. In summary, laboratory hazards can be anticipated in many, but not all situations. However, careful handling and use of chemicals, together with the availability of adequate and proper safety equipment, and the application of good practices in housekeeping and personal hygiene, will greatly reduce the probability and severity of injuries.

\section{REFERENCES}

[1] IUPAC-IPCS., Chemical Safety Matters. Cambridge University Press, England, 1992.

[2] Patrick Banse, P. \& Chris St. Cyr, E., Designing laboratory ventilation systems. Smith Seckman Reid Inc: Houston, 2014.

[3] Stricoff, S.S. \& Walters, D.B., Laboratory Health and Safety Handbook: A Guide for the Preparation of a Chemical Hygiene Plan. $2^{\text {nd }}$ ed., John Wiley \& Sons, Inc: New York, 1995.

[4] Committee on Prudent Practices \& National Academy Press, Prudent Practices in the Laboratory: Handling, and Disposal of Chemicals. National Academy Press: Washington, DC, US, 1995. 
[5] American Chemical Society \& Committee on Chemical Safety, Safety in Academic Laboratories. $4^{\text {th }}$ ed., American Chemical Society: Washington, DC, US, 1990.

[6] Pipitone, D.A., Safe Storage of Laboratory Chemicals. $2^{\text {nd }}$ ed., John Willey \& Sons: Inc. New York, US, 1991.

[7] Pipitone, D.A. \& Helberg, D.D., Safety Chemical Storage: A Pound of Preventions Is Worth a Ton of Trouble. J. Chem. 59, p. 159, 1982.

[8] Alaimo, R.J., Handbook of Chemical Health and Safety. American Chemical Society: Washintong, D.C., Oxford University Press. England, 2001.

[9] DiBerardinis, L.J., Guidelines for Laboratory Design: Health, Safety, and Environmental Considerations. Wiley: NY, 2013.

[10] U.S. Consumer Safety Product Commission, Department of Health and Human Services, Centers for Disease Control and Prevention, National Institute for Occupational Safety and Health. School Chemistry Laboratory Safety Guide. CPSC NIOSH Publication: US, 2006.

[11] International Labour Office., Safety in the Use of Chemicals at Work: An ILO code of practice. Geneva, Switzerland, 1993.

[12] Research Council, Prudent Practices in the Laboratory: Handling and Management of Chemical Hazards. National Academy Press, US, 2011.

[13] American Chemical Society, Safety in Academic Chemistry Laboratories: Accident Prevention for College and University Students. 7, A Publication of the American Chemical Society Joint Board - Council Committee on Chemical Safety, 1 US, 2003.

[14] Moran, L. \& Masciangioli, T., Chemical Laboratory Safety and Security A Guide to Prudent Chemical Management. Committee on Promoting Safe and Secure Chemical Management in Developing Countries, Board on Chemical Sciences and Technology Division on Earth and Life Studies, The National Academic Press: Washington, DC, 2010.

[15] Burnett, L., Lunn, G., \& Coico, R., Biosafety: Guidelines for Working with Pathogenic and Infectious Microorganisms. Current Protocols in Microbiology. On line: http://www.phac-aspc.gc.ca/lab-bio/res/psds-ftss/chlamydia-trachomatiseng.php. Accessed on: Sep. 2015.

[16] World Health Organization, Laboratory Biosafety Manual. World Health Organization: Geneva, 2004.

[17] Griffin, B., Laboratory Design Guide. $3^{\text {th }}$ ed., Elsevier, 2005.

[18] Hain, W., Laboratories: A Briefing and Design Guide. Taylor \& Francis Group: 2003.

[19] University of Harvard, Laboratory Safety Manual. Harvard Department of Chemistry and Chemical Biology: US, 2012.

[20] Safe Work Australia, Managing Risks of Hazardous Chemicals in the Workplace: Code of Practice. Safe Work: Australia, 2012.

[21] OSHA, Laboratory Safety Guidance. Occupational Safety and Health Administration U.S. Department of Labor: US, 2011.

[22] Davis, D., Laboratory Safety: A Self-Assessment Workbook. 1ed. ASCP Press: 2008

[23] Vecchio, D., Sasco A.J. \& Cann, C.I., Occupational Risk in Health Care and Research, American Journal of Industrial Medicine, 43, pp. 369-397, 2003.

[24] Young, J., Improving Safety in the Chemical Laboratory. Willey: NY, 1991.

[25] National Research Council \& Committee on Prudent Practices in the Laboratory, Prudent Practices in the Laboratory: Handling And Management of Chemical Hazards. National Academies Press: Washington, DC, 2011. 
[26] Luxon, S.G., Hazards in the Chemical Laboratory. Royal Society of Chemistry: Cambridge, 1992.

[27] Alaimo, R.J., Handbook of Chemical and Health and Safety. Oxford University Press, American Chemical Society, 2001.

[28] Chemical Institute of Canada \& Ordre des Chimistes du Quebec, Laboratory health and safety guidelines: An invaluable resource for all laboratory personnel. Chemical Institute of Canada: Ottawa,2003.

[29] National Research Council (U.S.) Committee on Promoting Safe and Secure Chemical Management in Developing Countries, National Research Council (US) Board on Chemical Sciences and Technology. \& National Research Council (US) Division on Earth and Life Studies. Culture of Safety in Academic Chemical Research. The National Academies Press: Washington, DC, 2014.

[30] Gottschall, W.C. \& Walters D.B., Laboratory Health and Safety Dictionary. Willey: NY, 2001.

[31] National Research Council (U.S.) Committee on Promoting Safe and Secure Chemical Management in Developing Countries., National Research Council (US) Board on Chemical Sciences and Technology, Promoting Chemical Laboratory Safety and Security in Developing Countries, National Academies Press: Washington, DC, 2010.

[32] Organization for Economic Cooperation and Development, Good Laboratory Practice: OECD Principles and Guidance for Compliance Monitoring. OECD: Paris, 2005.

[33] Najat, R. \& Ramnik, S., Manual of Laboratory Safety: Chemical, Radioactive, and Biosafety with Biocides. Jaypee Brothers Medical Publishers: New Delhi, 2013.

[34] NFPA, Standard 45. Fire Protection for Laboratories Using Chemicals. National Fire Protection Association: Boston, MA, 2000.

[35] Hewett, P., Industrial Hygiene Exposure Assessment: Data Analysis and Interpretation. In: Handbook of Chemical Health and Safety. American Chemical Society: Washington, DC, 2001.

[36] Cheremisinoff, N.P., Handbook of hazardous chemical properties. ButterworthHeinemann, Boston, MA, 2000.

[37] Sweet, E. \& Stuart, R., Identifying General Laboratory Ventilation Requirements Using a Control Banding Strategy. Division of Chemical Health and Safety of the American Chemical Society, Elsevier, 2013. 